\title{
Questionamentos à historiografia do cordel brasileiro
}

\author{
Questioning the historiography of Brazilian cordel literature
}

LUCIANO, Aderaldo. Apontamentos para uma história crítica do cordel brasileiro. Rio de Janeiro; São Paulo: Edições Adaga; Luzeiro, 2012, 96 p.

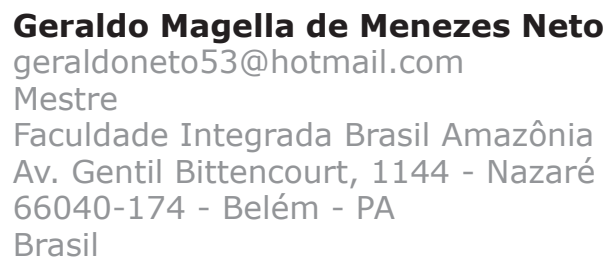

Geraldo Magella de Menezes Neto

geraldoneto53@hotmail.com

Mestre

Faculdade Integrada Brasil Amazônia

Av. Gentil Bittencourt, 1144 - Nazaré

66040-174 - Belém - PA

Brasil

Palavras-chave

Crítica; História; Literatura de cordel.

Keywords

220

Criticism; History; Cordel literature. 
O livro Apontamentos para uma história crítica do cordel brasileiro, de Aderaldo Luciano, é uma parte da tese de doutorado do autor em Ciência da Literatura pela Universidade Federal do Rio de Janeiro, defendida em 2009. Aderaldo Luciano é coordenador de vários projetos de divulgação sobre a literatura de cordel, como o 'Roda de Cordel: Círculo de Estudos Sobre o Cordel Brasileiro' e 'Roda de Cordel Leituras', projeto de leitura de cordéis em escolas e comunidades rurais brasileiras, além de ser preparador de originais da Ensinamento Editora. O autor também já foi coordenador editorial da Editora Luzeiro e um dos editores e colunistas da revista Confraria.

Como o próprio título da obra indica, a crítica é a marca do livro. A partir de várias questões relacionadas ao cordel, o autor contesta vários pesquisadores e dá a sua compreensão sobre a literatura de cordel brasileira. O objetivo, segundo Aderaldo Luciano, é o de "conduzir os estudos sobre o cordel norteando-os por sua filiação ao todo poético brasileiro" (LUCIANO 2012, p. 8). Desse modo, o autor almeja que os poetas de cordel sejam "citados lado a lado com os poetas clássicos de nossa literatura", fazendo uma crítica direta aos "manuais de literatura brasileira" por ignorarem os poetas de cordel, como Leandro Gomes de Barros (LUCIANO 2012, p. 8). O livro não deixa de ser um manifesto em favor dos poetas de cordel, e de protesto às instituições responsáveis em estabelecer o cânone literário brasileiro.

O autor aponta uma série de equívocos que, segundo ele, tem se propagado nas pesquisas sobre o cordel, tal como a ideia de que o mesmo tem uma origem ibérica, o que inclusive acabou por influenciar na adoção do termo 'cordel' a partir dos anos 1960. Aderaldo Luciano cita pesquisadores que repetem essa ideia da origem do cordel, tais como Umberto Peregrino, Manuel Diégues Junior, Sebastião Nunes Batista, Hélder Pinheiro e Joseph Luyten. O autor sugere que esses pesquisadores tenham sido influenciados por Sílvio Romero, "talvez o primeiro, em 1879, a fazer a comparação e mesmo propagar a igualdade" entre o cordel português e o brasileiro (LUCIANO 2012, p. 11).

No entanto, Aderaldo Luciano afirma que talvez não tenha ficado claro para alguns pesquisadores a qual cordel se referia Sílvio Romero. Para Luciano, Romero não se referia ao cordel nascido no Nordeste, já que em 1879 "ainda não se havia publicado folhetos de cordel no Brasil" (LUCIANO 2012, p. 12). Romero se referia "às produções brasileiras parafrásticas ou não das obras portuguesas", e o que se vendia pendurado em barbante na época era "livretos e não folhetos de cordel". Luciano conclui dizendo que "tomar o termo 'literatura de cordel' utilizado por Romero para nomear a produção cordelística brasileira resulta em equívoco" (LUCIANO 2012, p. 12).

Assim, Luciano identifica que o termo 'cordel' aparece primeiramente nos textos do pesquisador Teófilo Braga no século XVII se referindo a impressos que circulavam em Portugal, sendo a partir dele que estudiosos brasileiros passam a comparar o folheto brasileiro ao português (LUCIANO 2012, p. 15). Para Aderaldo Luciano, tal termo é "mal empregado em relação aos nossos folhetos de cordel, visto que são fenômenos distintos, havendo mais divergências do que semelhanças entre eles" (LUCIANO 2012, p. 83). 
Aderaldo Luciano também se opõe a vários temas recorrentes nas pesquisas sobre a literatura de cordel: a vinculação do cordel ao produto oral dos cantadores e repentistas, já que é "produto estritamente escrito, tendo inclusive o cordel influenciado as modalidades da cantoria" (LUCIANO 2012, p. 83); a vinculação entre o cordel e a poesia 'matuta', já que "o cordel apresentará, antes de mais nada, a regularidade estrófica" (LUCIANO 2012, p. 48); a vinculação entre o cordel e a xilogravura, mesmo sendo a xilogravura "um elemento no percurso do cordel", mas "de forma alguma é um eixo decisivo em sua formação, tampouco com ele (cordel) deve ser confundida" (LUCIANO 2012, p. 6); a ideia de que o cordel é uma poesia 'sertaneja', já que, para a formação do cordel concorreu "a confluência entre o sertão e a cidade" (LUCIANO 2012, p. 65); a distinção entre a literatura 'popular', a qual o cordel é associado, e a literatura erudita, já que para o autor essa distinção reside "na forma preconceituosa e excludente com que as elites intelectuais sempre trataram as produções que não saíssem de suas lides ou que não seguissem os seus ditames" (LUCIANO 2012, p. 17). Aderaldo Luciano aponta ainda que aspectos como o suporte, o conteúdo e a maneira como é vendido também não definem o que é o cordel.

As críticas mais fortes de Aderaldo Luciano ocorrem na questão da identificação de autoria dos folhetos de cordel. O autor critica pesquisadores que atribuem a autoria dos folhetos de Leandro Gomes de Barros a editores como João Martins de Ataíde, que, quando adquiriu os direitos das obras de Leandro, retirou o nome deste da capa dos folhetos, além de adulterar os

222 chamados acrósticos na última estrofe dos poemas. Luciano aponta que, apesar da autoria de Leandro ter sido restituída após várias pesquisas, "há estudiosos que continuam caindo no engano, movidos pela pressa e pela desatenção" (LUCIANO 2012, p. 73).

Luciano contesta, por exemplo, Irani Medeiros, que "comete erros tolos e graves devido à falta de rigor", pois considera "a poesia de Leandro como sertaneja", além de colocar na antologia de Leandro "textos de folhetos que não são do criador do cordel" (LUCIANO 2012, p. 74). Assim como o livro de Medeiros, Luciano aponta que a coleção da Editora Hedra, intitulada 'Biblioteca de Cordel', também comete equívocos na atribuição da autoria de folhetos. Para o autor, tais equívocos são resultados de "pesquisadores e estudiosos que não têm vivência e se recusam a conhecer as nuanças, os detalhes, do cordel" (LUCIANO 2012, p. 75), da "falta de averiguação das informações recebidas por alguns pesquisadores" e, "muitas vezes, a preguiça de pesquisar de certos estudiosos" (LUCIANO 2012, p. 77).

Para Aderaldo Luciano, o cordel deve ser estudado como uma literatura brasileira, não como uma literatura 'popular' e 'folclórica'. Luciano aponta que "os estudiosos do cordel foram incapazes de oferecer-lhe sua verdadeira dimensão literária" (LUCIANO 2012, p. 84). O autor adota o conceito de 'gêneros literários', no qual o cordel é "uma forma fixa da poesia que pode manifestar-se de formas distintas, sem pureza textual, com uma característica dominante: narrativo, dramático, lírico, etc" (LUCIANO 2012, p. 82). Sendo assim, para o autor, o cordel "é poesia e técnica, visto que forma fixa. O encontro da técnica e da poesia, do 
engenho e da arte, fará brotar a obra-prima do cordel" (LUCIANO 2012, p. 8). A partir dessa definição, o autor se opõe às classificações temáticas do cordel, que "são obsoletas em termos de literatura, servindo apenas para agrupamentos por temas, criando conjuntos que nada dizem" (LUCIANO 2012, p. 82). Assim, Luciano valoriza o papel do autor de cordel, "que deve ser respeitada como a de qualquer escritor que sinta a necessidade de escrever. Ao escritor cabe escrever sobre o quê e como lhe convier" (LUCIANO 2012, p. 83).

No entanto, ao mesmo tempo em que aponta erros nas obras de outros pesquisadores, o próprio livro de Aderaldo Luciano também apresenta vários equívocos. Primeiro, a afirmação de que desde os tempos de Sílvio Romero, no século XIX, com seus estudos sobre a poesia popular, passando por Gustavo Barroso, em 1921, até Umberto Peregrino, na década de 80 do século passado, "os estudos ficaram estáticos e se auto-reproduzindo" (LUCIANO 2012, p. 7). Ao valorizar o seu estudo em demasia, Aderaldo Luciano despreza uma série de pesquisas que abordaram a literatura de cordel das mais diversas formas desde os anos 1980, contribuindo para novos olhares sobre esta literatura: por exemplo, estudos dos pesquisadores "brasilianistas", como Candace Slater (1984), Mark Curran (2001), e Martine Kunz (2001); da área da antropologia, como Antonio Arantes (1982) e Ruth Brito Lêmos Terra (1983); da comunicação e estudos da cultura, como os estudos de Jerusa Pires Ferreira (1993) e Walmir de Albuquerque Barbosa (1996); da área da história cultural, da história do livro e da leitura e dos estudos literários, como as pesquisas de Ana Maria de Oliveira Galvão (2006), Vilma Mota Quintela (2005), Rosilene Melo (2010), Bruna Paiva Lucena (2010), etc.

Esses estudos, que representam uma pequena parcela do que foi produzido sobre a literatura de cordel a partir dos anos 1980, seguindo por vários caminhos diferentes dos pesquisadores citados pelo autor, foram completamente ignorados por Aderaldo Luciano. O que parece é que, para o autor, as pesquisas sobre o cordel ficaram restritas às dos pesquisadores vinculados à Casa de Ruy Barbosa, a exemplo de Veríssimo de Melo, Umberto Peregrino e Manuel Diégues Júnior, bastante significativas nos anos $1960-70 .{ }^{1}$ Nesse sentido, não se pode dizer que os estudos ficaram estáticos e se auto-reproduzindo; cada um compreende o cordel a sua maneira, já que o cordel não deixa de ser um objeto de estudo interdisciplinar. Entendemos que a construção dos conhecimentos sobre o cordel ocorreu a partir de um processo, e que mesmo quando não se concorda com as ideias de alguns pesquisadores, faz-se necessário reconhecer que eles também não deixaram de contribuir para um maior esclarecimento sobre essa manifestação literária, não cabendo ignorar tais estudos. O livro de Aderaldo Luciano, por fim, deixa de fazer referência a várias obras importantes para se compreender o cordel hoje.

\footnotetext{
${ }^{1}$ Segundo Bruna Paiva de Lucena, a historiografia do cordel brasileiro responsável pelo cânone do cordel tem por base as pesquisas da Fundação Casa de Ruy Barbosa, do estudioso francês Raymond Cantel e as que deram origem ao Dicionário bio-bibliográfico de repentistas e poetas de bancada, feitas por Átila de Almeida e José Alves Sobrinho, bem como a campanha nacional em defesa do folclore. A partir desses estudos, passou-se a "postular o conceito e os limites da 'literatura de cordel', também seus autores, seus meios legítimos de publicação, entre outros aspectos." No entanto, conforme observa Bruna Lucena, esse procedimento acabou por deixar "muito do lado de fora, como os cordéis de autoria de mulheres" (LUCENA 2010, p. 14).
} 
Não deixa de soar estranho, igualmente, o fato de o autor dizer que o estudo de Márcia Abreu, a tese intitulada Cordel português/folhetos nordestinos: confronto - um estudo histórico-comparativo, de 1993 (depois publicada no livro Histórias de cordéis e folhetos, de 1999), o qual é elogiado por Luciano, ter passado "despercebido por quase todos os estudiosos do cordel" (LUCIANO 2012 , p. 81). Ora, é só fazer uma rápida pesquisa nos estudos mais recentes sobre cordel para perceber que a obra de Márcia Abreu é uma das mais citadas, já que foi, possivelmente, o primeiro estudo a questionar a vinculação do cordel brasileiro ao cordel português.

Outra questão problemática abordada em Apontamentos para uma história crítica do cordel brasileiro é quando o autor tenta definir as "gerações" dos poetas de cordel, que para ele são três: "geração princesa" - a fundadora; "geração regente" - a continuadora; e "geração coroada" - a da atualidade (LUCIANO 2012, p. 5). A "geração coroada", para Aderaldo Luciano, inclui poetas como: Marco Haurélio, Klévisson Viana, Rouxinol do Rinaré, Moreira de Acopiara, Varneci Nascimento, João Gomes De Sá, Costa Senna, Cacá Lopes, Arievaldo Viana (LUCIANO 2012, p. 6).

Aqui cabe a pergunta: por que só são citados estes poetas como representativos da geração atual? Quais os critérios para essa escolha? Por que são deixados de fora uma série de poetas e poetisas que produzem cordel na atualidade? Essas questões não são esclarecidas no livro. Aqui fazemos referência a Márcia Abreu, que aponta que "por trás da definição de literatura está um ato de seleção e exclusão, cujo objetivo é separar alguns textos, escritos por alguns autores do conjunto de textos em circulação" (ABREU 2006, p. 39). Entretanto, na maior parte das vezes, "não são critérios linguísticos, textuais ou estéticos que norteiam essa seleção de escritos e autores", mas sim "a difícil questão do valor, que tem pouco a ver com os textos e muito a ver com posições políticas e sociais" (ABREU 2006, p. 39).

Nesse sentido, o autor se contradiz, pois ao mesmo tempo em que critica as antologias de cordel, afirmando que elas "são segregadoras, arrastando cada vez mais o cordel para o gueto", e de que devido a elas "a academia fechou suas portas" (LUCIANO 2012, p. 9), ele age da mesma forma, selecionando alguns poetas que considera como mais importantes para a história do cordel brasileiro, e 'fechando as portas' para um grupo considerável de outros poetas.

Apesar dessas ressalvas, Apontamentos para uma história crítica do cordel brasileiro tem o mérito de estimular a reflexão nos pesquisadores, já que questiona várias definições e generalizações sobre o cordel. A obra é quase como um manifesto em favor dos poetas de cordel, o que demonstra o envolvimento do autor com o seu objeto de estudo. Não sabemos se a pretensão do autor, de "conduzir os estudos sobre o cordel norteando-os por sua filiação ao todo poético brasileiro" (LUCIANO 2012, p. 8), irá se realizar, mas podemos dizer que a obra é mais um livro importante que se soma à historiografia sobre o cordel brasileiro, e que merece a atenção dos pesquisadores. 


\section{Referências bibliográficas}

ABREU, Márcia. História de cordéis e folhetos. Campinas: Mercado de Letras; Associação de Leitura do Brasil, 1999.

. Cultura letrada: literatura e leitura. São Paulo: Editora UNESP, 2006.

CURRAN, Mark. História do Brasil em cordel. 2a ed. São Paulo: Edusp, 2001.

ARANTES, Antonio Augusto. O trabalho e a fala (estudo antropológico sobre os folhetos de cordel). Campinas: Kairós; FUNCAMP, 1982.

BARBOSA, Walmir de Albuquerque. O cordel na Amazônia. Manaus: Editora da Universidade do Amazonas, 1996.

FERREIRA, Jerusa Pires. Cavalaria em cordel: o passo das águas mortas. $2^{a}$ ed. São Paulo: Hucitec, 1993.

GALVÃO, Ana Maria de Oliveira. Cordel: leitores e ouvintes. Belo Horizonte: Autêntica, 2006.

KUNZ, Martine. Cordel: a voz do verso. Fortaleza: Museu do Ceará/Secretaria da Cultura e Desporto do Ceará, 2001.

LUCENA, Bruna Paiva de. Espaços em disputa: o cordel e o campo literário brasileiro. Dissertação (Mestrado em Literatura e Práticas Sociais) Universidade de Brasília - UNB, Brasília, 2010.

MELO, Rosilene Alves de. Arcanos do verso: trajetórias da literatura de cordel. Rio de Janeiro: 7Letras, 2010.

QUINTELA, Vilma Mota. O cordel no fogo cruzado da cultura. Tese (Doutorado em Letras) - Universidade Federal da Bahia - UFBA, Salvador, 2005.

SLATER, Candace. A vida no barbante: a literatura de cordel no Brasil. Rio de Janeiro: Civilização Brasileira, 1984.

TERRA, Ruth Brito Lêmos. Memória de lutas: literatura de folhetos do Nordeste (1893-1930). São Paulo: Global Editora, 1983. 